\title{
Mechanism of Sodium and Chloride Transport in the Thin Ascending Limb of Henle
}

\author{
Masashi IMaI and Juha P. KoKko \\ From the Department of Internal Medicine, The University of Texas Health Science Center \\ at Dallas, Southwestern Medical School, Dallas, Texas 75235
}

A B S T R A C T Our previous in vitro studies have disclosed that the thin ascending limb of Henle (tALH) possesses some unique membrane characteristics. In those studies we failed to demonstrate active transport of sodium chloride by the tALH, although it was shown that the isotopic permeability to sodium and chloride was unusually high. However, we did not examine the mechanisms by which the apparent high permeation of sodium chloride occurs. Thus the purpose of the present studies was to elucidate the mechanism of sodium chloride transport across the isolated tALH of the rabbit by conducting four different types of studies: (1) comparison of the observed chloride and sodium flux ratios to those predicted by Ussing's equation under imposed salt concentration gradients; (2) kinetic evaluation of chloride and sodium fluxes; (3) examination of the effect of bromide on the kinetics of chloride transport; and (4) experiments to test for the existence of exchange diffusion of chloride. In the first set of studies the predicted and the theoretical flux ratios of sodium were identical in those experiments in which sodium chloride was added either to the perfusate or to the bath. However, the observed chloride flux ratio, lumen-to-bath/bath-to-lumen, was significantly lower than that predicted from Ussing's equation when $100 \mathrm{mM}$ sodium chloride was added to the bath. In the second set of experiments the apparent isotopic permeability for sodium and for chloride was measured under varying perfusate and bath $\mathrm{NaCl}$ concentrations. There was no statistical change in the apparent sodium permeability coefficient when the $\mathrm{NaCl}$ concentration was raised by

This work was presented in part at the meeting of the American Society of Nephrology, Washington, D. C., November, 1973.

Dr. Imai's present address is Department of Pharmacology, Jichi Medical School, 3311-1 Minamikawachi, Kawachi; Tochigi, Japan 329-04.

Received for publication 11 June 1974 and in revised form 3 August 1976. varying increments from 85.5 to $309.5 \mathrm{mM}$. However, permeation of ${ }^{36} \mathrm{Cl}$ decreased significantly with an increase in $\mathrm{Cl}$ from 73.6 to $598.6 \mathrm{mM}$. These events could be explained by a two component chloride transport process consisting of simple diffusion and a saturable facilitated diffusion process with a $V_{\max }$ $=3.71 \mathrm{neq} \mathrm{mm}^{-1} \mathrm{~min}^{-1}$. In the third set of studies it was shown that bromide inhibits transport of chloride and that the magnitude of inhibition is dependent on chloride concentrations. The fourth set of studies ruled out the existence of exchange diffusion.

In conclusion, these studies indicate that sodium transport across tALH is by simple passive diffusion, while chloride transport across tALH involves at least two mechanisms: (1) simple passive diffusion; and (2) a specific membrane interaction process (carrier-mediated) which is competitively inhibited by bromide.

\section{INTRODUCTION}

The thin ascending limb of Henle $(\mathrm{tALH})^{1}$ plays an important role in the over-all operation of the renal countercurrent multiplication system. In our earlier study (1), we failed to demonstrate the existence of active transport across the $\mathrm{ALH}$, but we did show that its passive permeability characteristics are different from those of the descending limb of Henle $(2,3)$. The tALH is highly permeable to $\mathrm{Na}^{+}$and $\mathrm{Cl}^{-}$, moderately permeable to urea, and virtually impermeable to the osmotic flow of water. Moreover, the permeability to chloride was noted to be much higher than the permeability to sodium.

The purpose of the present investigation is to extend the previous studies by examining in detail the nature of the passive transport mechanisms that regulate $\mathrm{NaCl}$ transport out of the in vitro perfused

\footnotetext{
${ }^{1}$ Abbreviations used in this paper: bl, bath to lumen; $\mathrm{lb}$, lumen to bath; PD, potential difference; tALH, thin ascending limb of Henle.
} 
tALH of the rabbit kidney. We have argued that solvent drag of $\mathrm{NaCl}$ was unlikely since this segment is impermeable to water (1). Therefore, the studies were designed to differentiate among the other passive transport mechanisms, i.e. simple passive diffusion, facilitated diffusion, exchange diffusion, and single file diffusion.

The results of the current studies reveal that transport of sodium occurs by simple passive diffusion, whereas a specific passive mechanism with membrane interaction is responsible, in part, for the transport of chloride.

\section{METHODS}

Isolated segments of the thin ascending limb of Henle were perfused in vitro by the same general techniques previously described (1). All nephron segments were obtained from 1.5-2.5 kg female New Zealand rabbits, which were maintained on a normal laboratory diet. Four groups of studies were conducted.

Flux ratio studies (Group I). The purpose of this series of studies was to examine whether the unidirectional flux ratios (lumen/bath) of ${ }^{22} \mathrm{Na}$ and ${ }^{36} \mathrm{Cl}$ were the same or different from those that would be predicted by the Ussing's equation (4) by using the simultaneously measured transtubular potential difference. Two subsets of studies were performed. In each case the solutions on both sides of the membrane were isosmolal to each other. In one set the bath was prepared by adding $100 \mathrm{mM} \mathrm{NaCl}$ to commercially available rabbit serum, while the isosmolality of perfusing ultrafiltrate was achieved by the addition of an osmotically equivalent amount of mannitol. In the second set of experiments $100 \mathrm{mM} \mathrm{NaCl}$ was added to the perfusing ultrafiltrate, while $100 \mathrm{mM}$ mannitol was added to the bathing rabbit serum. The results of these studies were compared to those of previously published studies (1), in which tubules were perfused with an isosmolal ultrafiltrate of the same rabbit serum as used for the bath (no $\mathrm{NaCl}$ gradient). In each case the bidirectional sodium fluxes were determined simultaneously by using ${ }^{22} \mathrm{Na}$ and ${ }^{24} \mathrm{Na}$. The bath-to-lumen and lumen-to-bath chloride fluxes were also obtained in these same tubules by using ${ }^{36} \mathrm{Cl}$ first in the perfusate and then in the bath, or vice versa. The chloride flux measurements were obtained sequentially instead of simultaneously since only one chloride isotope is practical for this type of study. In each experiment transtubular PD was measured simultaneously by techniques previously published $(5,6)$.

Kinetic analysis of sodium and chloride transport (Group II). The isotopic permeability coefficient and unidirectional efflux of ${ }^{22} \mathrm{Na}$ and ${ }^{36} \mathrm{Cl}$ were examined in tubules perfused with solutions containing different concentrations of $\mathrm{NaCl}$. In each case the perfusate and the bath were identical in composition except that $5 \%(\mathrm{vol} / \mathrm{vol})$ calf serum was added to the bath. The compositions common to these solutions were: $\mathrm{KCl} 5.0, \mathrm{NaHCO}_{3} 11.9$, Na acetate 10.0, $\mathrm{Na}_{2} \mathrm{HPO}_{4} \quad 0.32, \mathrm{MgCl}_{2} \quad 1.0, \mathrm{CaCl}_{2} \quad 1.8$, D-glucose $8.3, \mathrm{~L}-$ alanine $5.0 \mathrm{mM}$. To the parent solution either 63,137 , 287,449 , or $599 \mathrm{mM} \mathrm{NaCl}$ was added to achieve the different concentrations of $\mathrm{NaCl}$. Sucrose was added in appropriate amounts to the first two solutions to make their osmolality the same as that of the solution to which $287 \mathrm{mM} \mathrm{NaCl}$ was added. It was not possible to use a single tubule for $\mathrm{Na}$ and $\mathrm{Cl}$ flux measurement at all five concentrations of
$\mathrm{NaCl}$. This would have been ideal but not practical because of the length of time inherent in these types of experiments when both the perfusate and bath are changed. Therefore, two sets of experiments were conducted. The same tubules were used for the lower three concentrations of $\mathrm{NaCl}(63,137$, and $287 \mathrm{mM})$ while another set of tubules was used for the higher concentrations of $\mathrm{NaCl}(449$ and $599 \mathrm{mM})$. In the lower concentration studies both $\mathrm{Na}$ and $\mathrm{Cl}$ fluxes were measured. Since $\mathrm{Na}^{+}$but not $\mathrm{Cl}^{-}$transport followed the simple laws of diffusion over this wide $\mathrm{Na}^{+}$concentration range $(63-287 \mathrm{mM})$, the characteristics of $\mathrm{Cl}^{-}$transport only were evaluated at all five concentrations of $\mathrm{NaCl}$. To assure complete exchange of perfusate, each perfusate was exchanged at least three times by techniques previously described (6) before a new set of data was collected.

Effect of bromide on the kinetics of chloride transport (Group III). In this set of experiments the kinetics of $\mathrm{Cl}$ transport were examined for the same solutions as used in Group II experiments except that $100 \mathrm{mM} \mathrm{NaBr}$ was added to the perfusate and the bath during the experimental periods. Tubules were first perfused with $\mathrm{Br}$-free solution, then with solution containing $100 \mathrm{mM} \mathrm{NaBr}$, and again by Br-free solution to obtain recovery periods. In each case compositions of the bathing media were identical to those of the perfusate except that the former contained 5\% (vol/wt) calf serum. Three 10-min collections were obtained by using each perfusate. Isotopic ${ }^{36} \mathrm{Cl}$ flux from lumen to bath was determined during each period. The compositions common to the artificial solutions used in this group of experiments were: $\mathrm{KCl} 5.0, \mathrm{NaHCO}_{3} 5.0$, $\mathrm{Na}$ acetate 5.0, $\mathrm{Na}_{2} \mathrm{HPO}_{4} 0.32, \mathrm{MgCl}_{2} 1.0, \mathrm{CaCl}_{2} 1.8$, D-glucose 8.3, and $\mathrm{L}-$ alanine $5.0 \mathrm{mM}$. Chloride concentration was varied by adding 65,140 , or $290 \mathrm{mM}$ of $\mathrm{NaCl}$ to the parent solution. $100 \mathrm{mM} \mathrm{NaBr}$ was added to each "experimental" solution. To negate possible contribution of osmotic gradients to the observed results, $182 \mathrm{mM}$ of sucrose (instead of $\mathrm{NaBr}$ ) was added to the control solutions.

Exchange diffusion studies (Group IV). The permeability coefficient of ${ }^{36} \mathrm{Cl}$ was measured both with and without chloride in the bathing media. The perfusate in this series of experiments remained unchanged and contained: $\mathrm{NaCl}$ $140, \mathrm{~K}_{2} \mathrm{SO}_{4} 25, \mathrm{NaHCO}_{3}, 5.0, \mathrm{Na}$ citrate 1.4, $\mathrm{Na}_{2} \mathrm{HPO}_{4}$ 0.32 , Ca acetate $1.8, \mathrm{MgSO}_{4} 1.0$, D-glucose 8.8 and L-ananaine $5.0 \mathrm{mM}$. During control periods the bath was identical to the perfusate except that it contained $5 \%(\mathrm{rol} / \mathrm{vol})$ calf serum. The subsequent experimental periods were conducted by using a bath in which all of the $\mathrm{NaCl}$ was replaced by mannitol. In each tubule the ${ }^{36} \mathrm{Cl}$ permeability coefficients were determined during three control and three experimental periods.

The permeability coefficients, or lumen-to-bath (lb) isotopic fluxes normalized by ion concentration, were calculated according to the following equation (7) and expressed in terms of centimeters per second.

$$
P_{l b}=\frac{V_{i}-V_{o}}{A}\left[\frac{\ln \left(C_{i} / C_{o}\right)}{\ln \left(V_{i} / N_{0}\right)}+1\right]
$$

where $P=$ permeability coefficient $(\mathrm{cm} / \mathrm{sec}), V_{i}=$ perfusion rate $(\mathrm{nl} / \mathrm{min}), V_{o}=$ collection rate $(\mathrm{nl} / \mathrm{min}), A=$ surface area $\left(\mathrm{cm}^{2}\right), C_{i}=$ concentration of isotope in the perfusate $(\mathrm{cpm} / \mathrm{nl})$, $C_{o}=$ concentration of isotope in the collected fluid $(\mathrm{cpm} / \mathrm{nl})$. When net fluid movement was zero, the following equation was used (7):

$$
P_{l b}=\frac{V_{i}}{A} \ln \left(C_{i} / C_{o}\right)
$$


TABLE I

Analysis of Bidirectional Sodium and Chloride Fluxes when a $\mathrm{NaCl}$ Concentration Gradient Was Imposed across the tALH Epithelium

\begin{tabular}{|c|c|c|}
\hline $\begin{array}{c}\text { Perfusate } \\
\text { Bath }\end{array}$ & $\begin{array}{c}\text { Ultrafiltrate } \\
+ \\
\text { mannitol } \\
\text { Regular serum } \\
+ \\
\mathrm{NaCl}\end{array}$ & $\begin{array}{c}\text { Ultrafiltrate } \\
+ \\
\mathrm{NaCl} \\
\text { Regular serum } \\
+ \\
\text { mamnitol }\end{array}$ \\
\hline$\Phi_{\mathrm{ib}}^{\mathrm{Na}} /[\mathrm{Na}]_{1}, 10^{-5} \mathrm{~cm} / \mathrm{s}$ & $17.9 \pm 3.5$ & $31.1 \pm 4.8$ \\
\hline$\Phi_{\mathrm{h} 1}^{\mathrm{Na}} /[\mathrm{Na}]_{\mathrm{b}}, 10^{-5} \mathrm{~cm} / \mathrm{s}$ & $27.8 \pm 4.8$ & $22.7 \pm 3.9$ \\
\hline$\frac{\mathrm{lb}}{\mathrm{bl}}$ & $0.65 \pm 0.04$ & $1.40 \pm 0.05$ \\
\hline $\mathrm{PD}, m V$ & $-10.9 \pm 0.73$ & $+9.3 \pm 1.7$ \\
\hline $\exp \frac{\mathrm{zF}}{\mathrm{RT}} \Delta \Psi$ & $0.67 \pm 0.02$ & $1.42 \pm 0.04$ \\
\hline Number of experiments & 7 & 7 \\
\hline$\Phi_{\mathrm{lb}}^{\mathrm{Cl}} /[\mathrm{Cl}]_{1}, 10^{-5} \mathrm{~cm} / \mathrm{s}$ & $143.9 \pm 9.4$ & $128.3 \pm 19.3$ \\
\hline$\Phi_{\mathrm{hl}}^{\mathrm{Cl}} /[\mathrm{Cl}]_{\mathrm{b}}, 10^{-5} \mathrm{~cm} / \mathrm{s}$ & $124.6 \pm 7.7$ & $154.7 \pm 13.8$ \\
\hline $\mathrm{lb} / \mathrm{bl}$ & $1.16 \pm 0.05$ & $0.81 \pm 0.05$ \\
\hline $\mathrm{PD}, m V$ & $-10.8 \pm 0.49$ & $+9.1 \pm 0.69$ \\
\hline $\exp \frac{\mathrm{zF}}{\mathrm{RT}} \Delta \Psi$ & $1.50 \pm 0.03$ & $0.71 \pm 0.02$ \\
\hline Number of experiments & 7 & 6 \\
\hline
\end{tabular}

Abbreviations: $\Phi$, unidirectional flux in $\mathrm{cm} / \mathrm{s}, 1$, lumen; b, bath; lb, lumen-to-bath; bl, bath-to-lumen; lb/bl observed unidirectional flux ratios, $\exp \frac{\mathrm{ZT}}{\mathrm{RT}} \Delta \Psi$, theoretical lb/bl ratio using Ussing's equation (6).

Equations 1 and 2 gave essentially the same answers since the transtubular fluid movement was approximately zero during each experiment.

The permeability coefficient $\left(P_{b l}, \mathrm{~cm} / \mathrm{s}\right)$ was calculated by (1):

$$
P_{b l}=\frac{C_{o}{ }^{*}}{C_{b}}\left[\frac{P_{l b}}{l-\exp \left(-A P_{l b} N\right)}\right]
$$

where $C_{b}{ }^{*}=\mathrm{cpm} / \mathrm{nl}$ of isotope in the bath, and $V=$ the mean flow rate, $\left(V_{i}+V_{o}\right) / 2(\mathrm{nl} / \mathrm{min})$. Perfusion rate, $V_{i}$, was measured by using ${ }^{125}$ I-idothalamate (1). ${ }^{22} \mathrm{Na}$ and ${ }^{24} \mathrm{Na}$ were counted by using a Packard model 3365 threechannel gamma spectrometer, and ${ }^{36} \mathrm{Cl}$ and ${ }^{125} \mathrm{I}$ were assessed with a Packard model 2420 liquid scintillation counter (Packard Instrument Co., Inc., Downers Grove, IIl). When ${ }^{24} \mathrm{Na}$ was used in combination with other isotopes, ${ }^{24} \mathrm{Na}$ was counted immediately after the samples were obtained, while the other isotopes were counted 15 days later to allow for complete decay of ${ }^{24} \mathrm{Na}$. Short segments of tubules $(0.27 \pm 0.02 \mathrm{~mm})$ and relatively fast perfusion rates $(12.9 \pm 0.7 \mathrm{nl} / \mathrm{min})$ were used in the present series of studies to prevent tracer equilibrium.

Sodium concentration of the perfusate and the bathing medium was determined by an IL flame photometer (Instrumentation Laboratory Inc., Watertown, Mass.), and chloride concentration was determined by a BuchlerCotlove chloridometer (Buchler Instruments, Inc., Fort Lee, N. J.).

The data of each tubule were obtained as a mean of two or three collection periods. The results were expressed as a mean $\pm \mathrm{SE}$ of the number of tubules $(n)$ studied. The statistical analysis was performed using either a paired or nonpaired t-test.

\section{RESULTS}

Flux ratio studies (Group I). The results of these flux ratio studies are summarized in Table I. When the $\mathrm{NaCl}$ concentration of the bath was increased by addition of $100 \mathrm{mM} \mathrm{NaCl}$ to the bath, the ratio of $\mathrm{lb} / \mathrm{bl}$ of $\mathrm{Na}$ was $0.65 \pm 0.04$ as calculated from the unidirectional sodium fluxes (Table I). This value is not significantly different from the predicted value of $0.67 \pm 0.02$ as calculated by the Ussing's flux ratio equation by using the liquid-junction-corrected PD of $-10.9 \pm 0.73$ (Table I). However, similarly obtained $\mathrm{lb} / \mathrm{bl}$ ratios for chloride are significantly different from each other $(P<0.001)$ : the observed $\mathrm{lb} / \mathrm{bl}$ flux ratio was $1.16 \pm 0.05$, while the predicted $\mathrm{lb} / \mathrm{bl}$ chloride flux is $1.50 \pm 0.03$ as calculated from the PD of -10.8 \pm 0.49 (Table I).

When the perfusate concentration of $\mathrm{NaCl}$ was increased by the addition of $100 \mathrm{mM} \mathrm{NaCl}$ to the ultrafiltrate, $\mathrm{lb} / \mathrm{bl} \mathrm{Na}$ ratio was $1.40 \pm 0.05$, which again was not statistically different from the predicted $l b / b]$

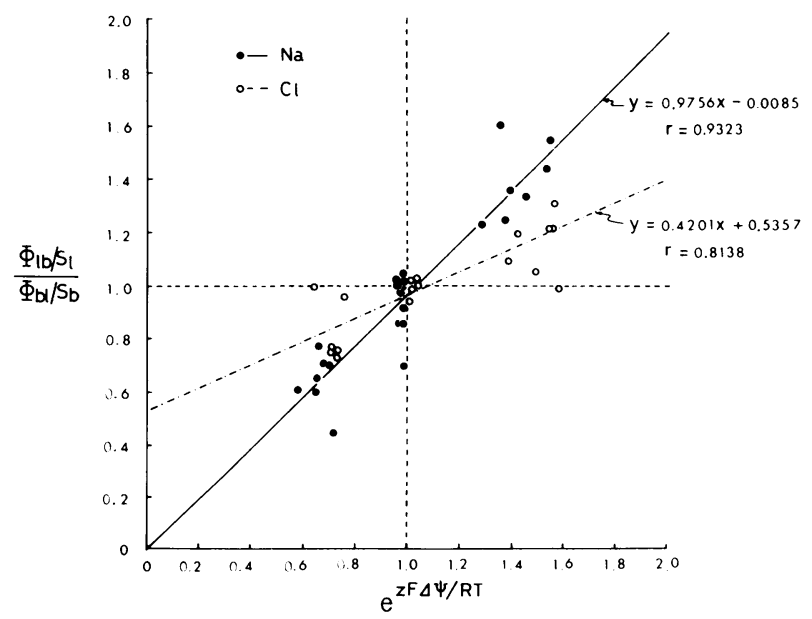

Figure 1 Flux ratio analysis of sodium and chloride transport across the thin ascending limb of Henle. The observed flux ratios normalized by concentration of respective ions (vertical axis) are plotted against the flux ratios predicted by transtubular PD (horizontal axis). $S_{1}$ and $S_{b}$ denote $\mathrm{Na}^{+}$or $\mathrm{Cl}^{-}$concentration in the lumen and the bath, respectively. 
Table II

Permeability Coefficient and Flux of Sodium as a Function of NaCl Concentration of the Perfusate and Bath

\begin{tabular}{lccc}
\hline [NaCl] & 75.5 & 159.5 & 309.5 \\
\hline \multirow{2}{*}{$m M$} & & & \\
$\Phi_{\mathrm{Na}} /[\mathrm{Na}], 10^{-5} \mathrm{~cm} / \mathrm{s}$ & 21.7 & 23.2 & 26.5 \\
& \pm 4.7 & \pm 2.8 & \pm 3.1 \\
$\Phi_{\mathrm{Na}}$, neq $\mathrm{mm}^{-1} \mathrm{~min}^{-1}$ & 0.70 & 1.40 & 3.09 \\
& \pm 0.15 & \pm 0.17 & \pm 0.35 \\
$\mathrm{~N}$ & 7 & 7 & 7 \\
\hline
\end{tabular}

Abbreviations: $\Phi_{\mathrm{Na}}$, flux of sodium; $\Phi_{\mathrm{Na}} /[\mathrm{Na}]=\mathrm{P}_{\mathrm{Na}}=$ permeability coefficient of sodium; $\mathrm{NaCl}$ concentration of perfusate and bath are equal, see text.

$\mathrm{Na}$ ratio of $1.42 \pm 0.04$ (Table I). Although the isotopically obtained $\mathrm{lb} / \mathrm{bl} \mathrm{Cl}$ ratio was $0.81 \pm 0.05$, this value was not statistically different from the electrophysiologically predicted value of $0.71 \pm 0.02$ (Table I).

To analyse the data more in detail, the observed flux ratios were plotted against what would be predicted on the basis of the Ussing equation (Fig. 1). The data obtained from our previously published paper (1), in which there was no transtubular electrochemical gradient, as well as our current experimental results, are depicted in Fig. 1. This pooled data was used to calculate the regression lines. The slope of the line of $\mathrm{Na}, 0.9756$, is not different from 1.0 and thus is close to the line of identity. On the other hand, the regression line for chloride clearly deviates from the line of identity having a slope of 0.4201 ( $P$ $<0.005$ ). These data strongly suggest that sodium is transported by simple passive mechanism, whereas chloride transport does not follow the principles of simple passive diffusion.

Kinetic analysis of sodium and chloride trans- port (Group II). Table II summarizes the results of experiments in which isotopic sodium permeability was examined as a function of luminal concentration of sodium. The luminal and bath sodium concentrations were $75.5,159.5$, and $309.5 \mathrm{mM}$, respectively. It is evident from these results that the normalized isotopic sodium flux $\left(\Phi_{\mathrm{Na}} /[\mathrm{Na}]\right)$ does not change with variation in luminal sodium concentration. Thus, sodium fluxes across the tALH follow the principles of Fick's law.

In contrast, the normalized $\mathrm{Cl}$ flux $\left(\Phi_{\mathrm{Cl}} /[\mathrm{Cl}]\right)$ decreased with increasing luminal chloride concentration, Table III. When this finding is expressed in terms of flux, Fig. 2, it is clear that the chloride fluxes fall below the line that would be predicted by Fick's law (shaded area of Fig. 2). From the results shown in Fig. 2, it can be

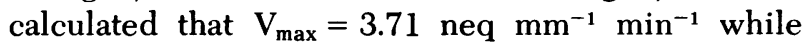
the permeability coefficient for ${ }^{36} \mathrm{Cl}=92.9 \times 10^{-5}$ $\mathrm{cm} / \mathrm{sec}$.

Effect of bromide on the chloride transport (Group) III). The effect of $100 \mathrm{mM} \mathrm{NaBr}$ on the unidirectional efflux of chloride was examined to see if the chemically similar ion may also inhibit ${ }^{36} \mathrm{Cl}$ transport. The results of these experiments are graphically depicted in Fig. 3. On the vertical axis is plotted the ${ }^{36} \mathrm{Cl}$ flux expressed in units of $10^{-5} \mathrm{~cm} /$ sec (normalized by $\mathrm{Cl}^{-}$concentrations). It is quite clear from these data that ${ }^{36} \mathrm{Cl}$ transport is inhibited by the presence of $\mathrm{NaBr}$. The inhibitory effect of $\mathrm{NaBr}$ on ${ }^{36} \mathrm{Cl}$ flux is largest at the lowest $\mathrm{Cl}^{-}$concentration, Table IV.

Exchange diffusion studies (Group IV). The magnitude of the ${ }^{36} \mathrm{Cl}$ permeability coefficient was measured in the complete absence of $\mathrm{Cl}^{-}$in the bath to determine whether exchange diffusion is the mechanism responsible for the observed high permeability to ${ }^{36} \mathrm{Cl}$. The results of these experiments are summarized in Table IV and show that with complete removal of $\mathrm{NaCl}$ from the bath (mannitol replacement)

TABLE III

Permeability Coefficient and Flux of Chloride as a Function of $\mathrm{NaCl}$ Concentration of the Perfusate and Bath

\begin{tabular}{lcccccc}
\hline$[\mathrm{NaCl}]$ & $\mathrm{mM}$ & 75.5 & 159.5 & 309.5 & 448.6 & 598.6 \\
\hline$\Phi_{\mathrm{Cl}} /[\mathrm{Cl}]$ & $10^{-5} \mathrm{~cm} / \mathrm{s}$ & 187.9 & 165.1 & 122.2 & 115.1 & 103.6 \\
& & \pm 19.0 & \pm 15.0 & \pm 13.0 & \pm 14.1 & \pm 9.1 \\
$\Phi_{\mathrm{Cl}}$ & neq $\mathrm{mm}^{-1} \mathrm{~min}^{-1}$ & 5.21 & 9.18 & 13.78 & 19.46 & 24.90 \\
& & \pm 0.53 & \pm 0.84 & \pm 1.46 & \pm 2.38 & \pm 1.66 \\
$\mathrm{~N}$ & & 6 & 7 & 6 & $6^{*}$ & $6^{*}$ \\
\hline
\end{tabular}

Abbreviations: $\Phi_{\mathrm{Cl}}$ flux of chloride; $\Phi_{\mathrm{Cl}} /[\mathrm{Cl}]=\mathrm{P}_{\mathrm{Cl}}=$ permeability coefficient of chloride; $\mathrm{NaCl}$ concentration of perfusate and bath are equal, see text.

* Separate series of studies. 
the chloride flux decreased from 7.12 to 3.98 neq $\mathrm{mm}^{-1} \mathrm{~min}^{-1}$. However, the luminal PD became $+4.64 \mathrm{mV}$ with mannitol substitution for $\mathrm{NaCl}$; and this newly generated diffusion PD would act as an inhibitory force for efflux of ${ }^{36} \mathrm{Cl}$. To make an appropriate comparison of ${ }^{36} \mathrm{Cl}$ fluxes, the ${ }^{36} \mathrm{Cl}$ flux must be corrected for the PD between the two experimental conditions. When this correction was made, the chloride efflux actually appeared to be somewhat higher than it was before $\mathrm{NaCl}$ removal; however, these differences were not statistically significant (Table V). Thus, this group of studies would constitute evidence against exchange diffusion.

\section{DISCUSSION}

The mechanism of solute transport across biological membranes may be classified broadly as being either active or passive in nature. Though a precise definition of active transport is difficult to express, it is

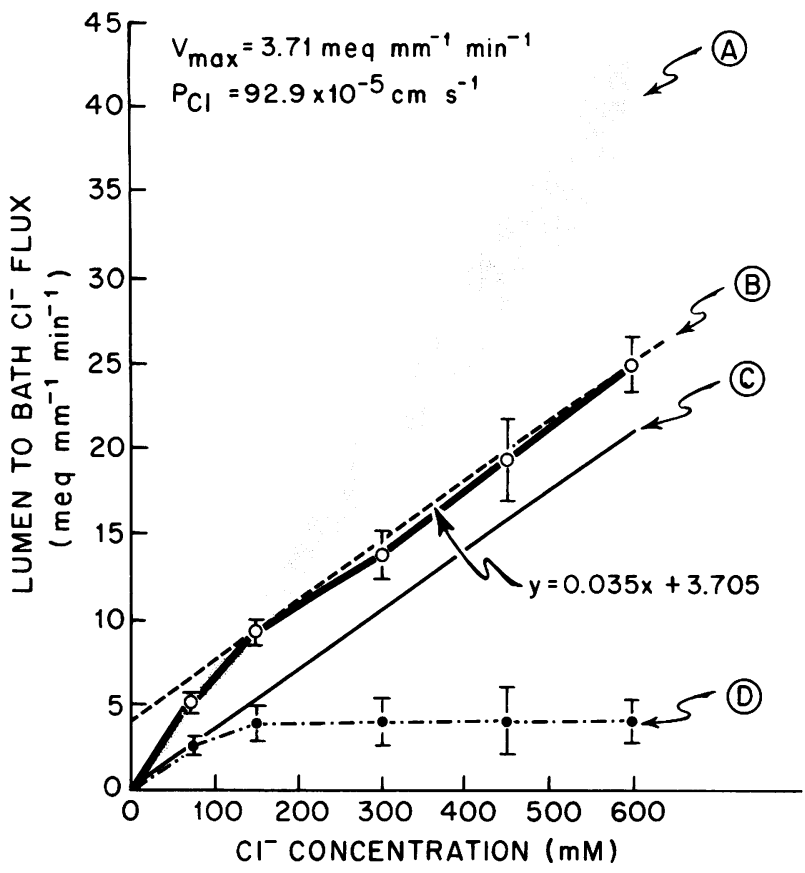

Figure 2 Lumen to bath chloride flux (vertical axis) as a function of ambient chloride concentration (horizontal axis), $\mathbf{A}=$ shaded area which indicates a range of chloride flux calculated from the mean and SE obtained at the lowest chloride concentration based on the assumption that the chloride transport is in accord with simple massive diffusion. $\mathrm{B}=$ experimentally determined points $\pm \mathrm{SE} . \mathrm{C}=$ parallel line to $B$ which indicates the simple passive component of transport depicted by $\mathrm{B} . \mathrm{D}=\mathrm{B}$ minus $\mathrm{C}$ which reflects the component of chloride transport which follows saturation kinetics. Calculated $V_{\max }=3.71 \mathrm{neq} \mathrm{mm}^{-1} \mathrm{~min}^{-1}$. No exact $K_{m}$ can be obtained since only one point was obtained at concentration of chloride that was below saturation value. The calculated normalized $\mathrm{Cl}^{-}$flux (normalized by $\mathrm{Cl}$ concentration) $=92.5 \times 10^{-5} \mathrm{~cm} / \mathrm{s}$ from line $\mathrm{C}$.
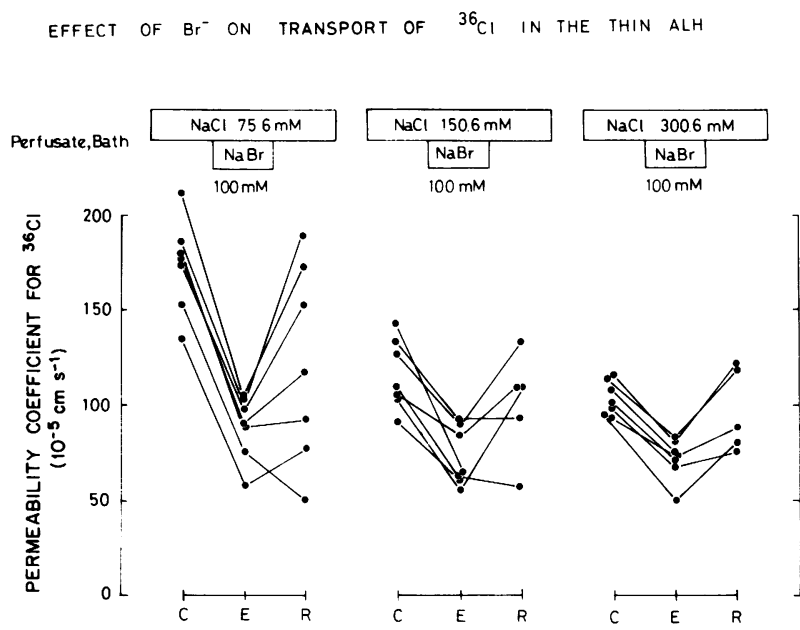

Figure 3 Effect of bromide on ${ }^{36} \mathrm{Cl}$ transport in the thin ascending limb of Henle. C, E, and R indicate control, experimental, and recovery periods, respectively.

generally accepted that active transport has been demonstrated if a membrane is capable of net transport of solute in the absence of electrochemical driving forces (absence of transepithelial concentration or potential gradients), or if the transport of solute is not coupled to active transport of other constituents. Although exceptions to this formulation may be made (8), it is a useful working definition. In previous studies we failed to demonstrate active transport of $\mathrm{NaCl}$ (1) by the in vitro perfused tALH. Furthermore, the tALH was shown to be impermeable to osmotic flow of water and quite permeable to sodium and chloride (1). The isotopic chloride permeability was about 3.8 times as great as the isotopic sodium permeability (1). Thus, the purpose of this paper was to define the nature of passive transport processes that regulate sodium and chloride transport out of the tALH.

Passive transport processes may be divided into four general categories: (1) transport of solute in association with bulk movement of fluid (solvent drag); (2) simple passive diffusion following the principles of Fick's law; (3) carrier-mediated transport mechanisms; or (4) single file diffusion. Since the tALH courses through regions of large osmotic gradients, it might be argued that solvent drag of fluid should play a role in transport of solutes. However, because this segment is impermeable to the osmotic flow of water $(1,9,10)$, it is not likely that solvent drag contributes significantly to transport of solutes across the tALH. The experimentally determined ratio of unidirectional sodium fluxes was in accord with those predicted by Ussing's equation (Fig. 1). In addition, the isotopic permeability coefficient of sodium was unchanged when the concentration of sodium was 
TABLE IV

Effect of $\mathrm{NaBr}(100 \mathrm{mM})$ on the Lumen-to-Bath Chloride Flux in the tALH*

\begin{tabular}{|c|c|c|c|c|c|c|}
\hline \multirow{2}{*}{$\begin{array}{c}\mathrm{NaCl} \\
\text { concentration }\end{array}$} & \multirow[b]{2}{*}{$x$} & \multicolumn{3}{|c|}{$\mathrm{PCl}$} & \multicolumn{2}{|c|}{$\phi \mathrm{Cl}$} \\
\hline & & $\mathrm{C}$ & $\mathrm{E}$ & (C-E) & C & E \\
\hline$m .1$ & & \multicolumn{3}{|c|}{$10^{-5} \mathrm{~cm} / \mathrm{s}$} & \multicolumn{2}{|c|}{ ne'l $\mathrm{mm}^{-1} \min 1$} \\
\hline 75.6 & 7 & 172.6 & 87.1 & 85.4 & 4.92 & 2.48 \\
\hline & & \pm 9.2 & \pm 6.4 & \pm 4.0 & \pm 0.26 & \pm 0.18 \\
\hline 150.6 & 7 & $\begin{array}{r}114.9 \\
\pm 6.9\end{array}$ & $\begin{array}{r}72.1 \\
\pm 5.8\end{array}$ & $\begin{array}{r}42.0 \\
\pm 6.9\end{array}$ & $\begin{array}{r}6.53 \\
\pm 0.40\end{array}$ & $\begin{array}{r}4.09 \\
\pm 0.33\end{array}$ \\
\hline 300.6 & 7 & $\begin{array}{r}104.3 \\
\pm 3.6\end{array}$ & $\begin{array}{r}72.1 \\
\pm 4.3\end{array}$ & $\begin{array}{r}32.2 \\
\pm 2.9\end{array}$ & $\begin{array}{r}11.82 \\
\pm 0.41\end{array}$ & $\begin{array}{r}8.17 \\
\pm 0.49\end{array}$ \\
\hline
\end{tabular}

Abbreviations: $\mathrm{PCl}$, permeability coefficient of chloride; $\phi \mathrm{Cl}$ (lb), unidirectional flux of chloride; $\mathrm{C}$, control periods in which perfusate does not contain $\mathrm{NaBr}$; $\mathrm{E}$, experimental periods in which perfusate contains $100 \mathrm{mM} \mathrm{NaBr}$.

Recovery values are not included under control periods. The reversible nature of these experiments is illustrated in Fig. 3.

varied (Table II). These findings strongly suggest that the transport of sodium across tALH is by simple passive diffusion. However, the unidirectional flux ratios of chloride are not in accord with values predicted by Ussing's equations (Fig. 1). This does not necessarily imply that chloride transport is an active process but only that chloride transport occurs by a mechanism that requires interaction with the tALH epithelium. Indeed the data of Fig. 2 suggest that ${ }^{36} \mathrm{Cl}$ transport is competitively inhibited by increasing chemical concentration of unlabeled chloride suggesting the existence of some carrier mediated mechanism. The data of Table II and Table III also exclude the possibility of single file diffusion for $\mathrm{Na}^{+}$and $\mathrm{Cl}$; if single file diffusion were to exist the permeability coefficient of chloride should increase as the concentration of luminal chloride was increased.

Carrier-mediated mechanisms, in turn, can be divided into three types: (1) active transport; (2) facilitated transport; and (3) exchange diffusion. In our previous report we were unable to show any evidence for active salt transport (1). In those studies, however, there was net transport of $\mathrm{NaCl}$ out of the tALH when the segments were perfused with isosmolal but hypernatremic solutions (isosmolality of the bath was maintained by addition of urea) (1). Thus those studies suggested, but admittedly did not prove, that chloride was transported by a facilitated transport mechanism instead of by exchange diffusion. The present group of studies shows that ${ }^{36} \mathrm{Cl}$ flux did not decrease with complete removal of $\mathrm{NaCl}$ from the bath (Table V). If exchange diffusion was operative in the transport of chloride, the chloride flux should decrease with the removal of $\mathrm{NaCl}$ from the bath. Thus, these results suggest that transport rate of ${ }^{36} \mathrm{Cl}$ across the tALH occurs by a facilitated transport mechanism and not by exchange diffusion.

Additional evidence for a carrier-mediated transport process for chloride is provided by the data showing that inhibition of ${ }^{36} \mathrm{Cl}$ transport by bromide is dependent on unlabeled chloride concentration (Fig. 3, Table IV). We therefore suggest that bromide may be a competitive inhibitor of chloride transport.

Facilitated transport is a unique passive transport mechanism which has the following characteristics (11): (a) the system operates in such a way as to dissipate electrochemical gradients of the permeant ion and requires no other source of free energy; (b) the rate of permeation of the ion in question is greater than could be expected from the number of hydrogen-bonding groups present across the penetrating probe molecule; $(c)$ the rate of permeation may not be expected to be directly proportional to the concentration but may reach a limiting (saturation) value as concentration is increased; $(d)$ the rate of permeation may be markedly reduced by the presence of molecules structurally analogous to the permeant considered; $(e)$ the rate of permeation may also be markedly and specifically reduced by the presence of substances differing chemically from the permeant; and $(f)$ the rate of permeation of permeant measured as net flux may be different from that determined isotopically as unidirectional flux.

Although we did not specifically analyze all of the above-mentioned criteria, we did show the presence of features a, c and d, which are essential characteristics in suggesting the existence of facilitated transport. Facilitated transport, or carrier-mediated transport in a more broad sense, is not uncommon in the kidney. Sodium is partly transported by co-trans-

TABLE V

The Response of Lumen-to-Bath Chloride Flux $\Phi \mathrm{Cl}(\mathrm{lb})$ to Removal of Chloride* from the Bath: Evidence Against Exchange Diffusion

\begin{tabular}{lccc}
\hline & Control & Experimental & Recovery \\
\hline $\mathrm{Cl}^{-}$Perfusate, $m M$ & 140.0 & 140.0 & 140.0 \\
$\mathrm{Cl}^{-}$Bath, $m M$ & 140.0 & 0 & 140.0 \\
$\mathrm{PD}, m V$ & $-0.3 \pm 0.3$ & $+46.4 \pm 1.7$ & $+0.2 \pm 0.2$ \\
$\Phi \mathrm{Cl}(\mathrm{lb})$, & $7.12 \pm 1.01$ & $3.98 \pm 0.83$ & $6.54 \pm 1.06$ \\
$n e q \mathrm{~mm}^{-1} \mathrm{~min}^{-1}$ & & $(P<0.002) \ddagger$ & \\
& & $10.80 \pm 2.31 \S$ & \\
& & $(P>0.05) \ddagger$ &
\end{tabular}

* Isosmolal replacement of bath $\mathrm{NaCl}$ by mannitol.

$\ddagger$ Flux was corrected by PD as $(\mathrm{RT} / \mathrm{F} \Delta \Psi) \exp (\mathrm{F} \Phi \Psi / \mathrm{RT})$ $-1 \Phi C l(l b)$.

$\S$ The data are compared with the control value. 
port mechanisms with glucose $(6,12-14)$ and amino acids $(6,15-18)$ in the proximal convoluted tubule. Folic acid by the dog kidney (19) and uric acid by the snake tubule (20) have also been reported to be transported by facilitated transport mechanisms. It is also of interest to note that chloride is actively transported in the thick ascending limb of Henle $(21,22)$. Since basic kinetic characteristics of active transport are essentially the same as those of facilitated transport mechanisms, this may be taken as another example of $\mathrm{a} \mathrm{Cl}^{-}$specific membrane carrier. The principal difference between active transport and passive facilitated transport mechanisms is that the former requires energy and is capable of net transport in the absence of favorable electrochemical potential difference.

In summary, the present studies have further characterized the mechanisms regulating $\mathrm{NaCl}$ transport out of the tALH. It was shown that sodium is transported by simple passive mechanisms while a carriermediated mechanism exists in the tALH which facilitates the transport of chloride. The carrier-mediated mechanism has a high capacity as noted by the $V_{\max }$ of 3.7 neq $\mathrm{mm}^{-1} \mathrm{~min}^{-1}$. In addition, though we could not obtain a precise estimate of the affinity of this carrier system, it was shown that the maximum value of $K_{m}$ indicates that the carrier system has a high affinity for chloride. At present the physiological significance of the newly identified transport process must remain conjectural. It is proposed that the existence of this carrier-mediated transport mechanism for chloride allows a relatively efficient passive transport of chloride out of the thin ascending limb of Henle. Since it has previously been proposed that the fluid entering the tALH has a $\mathrm{NaCl}$ concentration higher than the adjacent interstitium (23), this facilitated transport mechanism would be partly responsible for generating high interstitial osmolalities which are necessary for formation of maximally concentrated urine.

\section{ACKNOWLEDGMENTS}

This work was supported in part by U. S. Public Health Service Program grant PO 1 HL 11661, National Institute of Arthritis and Metabolic Diseases Research grant 1 ROI AM 14677, and National Institute of General Medical Sciences Research Fellowship grant 1 T22 GM 00034.

\section{REFERENCES}

1. Imai, M., and J. P. Kokko. 1974. Sodium chloride, urea, and water transport in the thin ascending limb of Henle. Generation of osmotic gradients by passive diffusion of solutes. J. Clin. Invest. 53: 393-402.

2. Kokko, J. P. 1970. Sodium chloride and water transport in the descending limb of Henle. J. Clin. Invest. 49: 1838- 1846.

3. Kokko, J. P. 1972. Urea transport in the proximal tubule and the descending limb of Henle. J. Clin. Invest. 51: 1999-2008.
4. Ussing, H. H. 1950. Distinction by means of tracers between active transport and diffusion. The transfer of iodide across the isolated frog skin. Acta Physiol. Scand. 19: 43-56.

5. Kokko, J. P., and F. C. Rector. 1971. Flow dependence of transtubular potential difference in isolated perfused segments of rabbit proximal convoluted tubule. J. Clin. Invest. 50: 2745-2750.

6. Kokko, J. P. 1973. Proximal tubular potential difference. Dependance on glucose, $\mathrm{HCO}_{3}$ and amino acids. $J$. Clin. Invest. 52: 1362-1367.

7. Grantham, J. J., and M. B. Burg. 1966. Effect of vasopressin and cyclic AMP on permeability of isolated collecting tubules. Am. J. Physiol. 211: 255-259.

8. Bresler, E. H. 1967. On criteria for active transport. J. Theor. Biol. 16: 135-146.

9. Morgan, T., and R. W. Berliner. 1968. Permeability of the loop of Henle, vasa recta and collecting duct to water, urea and sodium. Am. J. Physiol. 215: 108-115.

10. Sakai, F., M. Tadokoro, and M. Teraoka. 1971. Experimentelle Untersuchungen uber die Funktion des Nierenmarkes mit der Mikropunktionsmethods. Tokyo J. Med. Sci. 79: 1.

11. Stein, W. D. 1967. The movement of molecules across cell membranes. Academic Press, New York and London. 369.

12. Vogel, G., F. Lauterback, and W. Kröger. 1965. Die Bedeutung des Natriums für die renalen Transporte von Glucose und Para-aminohippursäure. Pfluegers Arch. 283: 151-159.

13. Vogel, G., U. Tervooren, and I. Stoeckert. 1966. Untersuchugen zur Abhängigkeit der renal tubulären GlucoseTransportes von lonen-Angebot sowie des $\mathrm{Na}^{+}$-Transportes vom Angebot an Glucose. Pfluegers Arch. 288: $359-368$.

14. Ruedas, G., and C. Weiss. 1967. Die Wirkung von Abhängigkeit der Natriumkonzentration im Perfusionsmedium und von Strophanthin auf die Glucose-resorption der isolierten Rattenniere. Pfluegers Arch. 298: $12-22$.

15. Rosenberg, L. E., A. Blair, and S. Segal. 1961. Transport of amino acids by slices of rat-kidney cortex. Biochim Biophys. Acta. 54: 479-488.

16. Fox, M., S. Thier, L. Rosenberg, and S. Segal. 1961. Ionic requirements for amino acid transport in the rat kidney cortex slice. I. Influence of extracellular ions. Biochim. Biophys. Acta. 79: 167-176.

17. Scriver, C. R., and F. Mohyuddin. 1968. Amino acid transport in kidney. Heterogeneity of $\alpha$-aminoisobutyric uptake. J. Biol. Chem. 243: 3207-3213.

18. Hillman, R. E., I. Albrecht, and L. E. Rosenberg. 1968. Transport of amino acids by isolated rabbit renal tubules. Biochim. Biophys. Acta. 150: 528-530.

19. Goresky, C. A., H. Watanabe, and D. G. Johns. 1963. The renal excretion of folic acid. J. Clin. Invest. 42: 1841- 1849 .

20. Danzler, W. D. 1973. Characteristics of urate transport by isolated perfused snake proximal renal tubules. Am. J. Physiol. 224: 445-453.

21. Rocha, A. S., and J. P. Kokko. 1973. Sodium chloride and water transport in the medullary thick ascending limb of Henle. Evidence for active chloride transport. J. Clin. Invest. 52: 612-623.

22. Burg, M. B., and N. Green. 1973. Function of the thick ascending limb of Henle's loop. Am. J. Physiol. 224: $659-668$.

23. Kokko, J. P., and F. C. Fector, Jr. 1972. Countercurrent multiplication system without active transport in inner medulla. Kidney Int. 2: 214-223. 